\title{
Co-occurrence of thyroid binding globulin excess and a pituitary macroadenoma containing thyroid stimulating hormone-producing cells
}

\section{Soubhi Nizam, L Kennedy}

A patient is described in whom thyroid binding globulin (TBG) excess was found in association with a pituitary macroadenoma containing thyroid stimulating hormone (TSH)-producing cells, and the potential for diagnostic confusion arising from this unusual combination of endocrine disorders is discussed. The patient presented with visual field disturbance, and magnetic resonance imaging led to the diagnosis of a pituitary tumour. Raised levels of total thyroxine and triiodothyronine along with normal TSH levels suggested the possibility of a TSH-secreting pituitary adenoma. Immunostaining of the tumour removed at transsphenoidal surgery confirmed the presence of TSHproducing cells. When raised total thyroxine and triiodothyronine levels persisted postoperatively, the diagnosis of TBG excess was confirmed. Use of free, rather than total, thyroid hormone assays would almost certainly have prevented the diagnostic confusion concerning possible TSH-secreting pituitary adenoma, but may have resulted in the TBG excess being overlooked entirely.

T hyroid stimulating hormone (TSH)-secreting pituitary tumours are rare, accounting for no more than $2 \%-3 \%$ of all pituitary adenomas. ${ }^{1}$ The classical findings are mild to moderately severe hyperthyroid symptoms, raised thyroid hormone levels, "normal" or modestly raised serum TSH, and radiological evidence of a pituitary adenoma, most commonly a macroadenoma. ${ }^{2}{ }^{3}$ Primary thyroid binding globulin (TBG) excess is also a rare disorder, usually inherited as an X-linked trait, ${ }^{4}$ with an incidence of about 1:25 000. ${ }^{5}$ Patients with this condition have raised total levels of thyroxine and triiodothyronine, normal levels of TSH, and are usually clinically euthyroid. The patient in this report had both a pituitary adenoma and excess TBG, and we highlight the potential for diagnostic confusion caused by their co-occurrence.

\section{CASE REPORT}

A 66 year old man presented with visual field loss in his left eye, headaches, decreased sexual drive, and erectile dysfunction. He was on no medications. He had no classical symptoms of hyperthyroidism or adrenal insufficiency. There was no known family history of pituitary or thyroid disease. A left inferior temporal visual field defect was confirmed by perimetry. He had normal secondary sexual characteristics, and was clinically euthyroid with no palpable goitre. Magnetic resonance imaging (MRI) revealed a $2.5 \mathrm{~cm}$ diameter lesion in the pituitary (fig 1). The referring physician found total thyroxine $152 \mathrm{nmol} / \mathrm{l}(58-155)$, total triiodothyronine $3.39 \mathrm{nmol} / \mathrm{l}(1.3-3.0)$, and TSH $3.3 \mathrm{mIU} / \mathrm{l}$ $(0.06-5.0)$. At our clinic the serum prolactin was $475 \mathrm{pmol} / \mathrm{l}$ (182-817), $1500 \mathrm{~h}$ cortisol $0.1 \mu \mathrm{mol} / \mathrm{l}(0.14-0.7)$, testosterone $0.8 \mathrm{nmol} / \mathrm{l}$ (9.45-37.45), follicle stimulating hormone (FSH)
$6.6 \mathrm{mIU} / \mathrm{ml}$ (1.3-19.3), and luteinising hormone $<3.0 \mathrm{mIU} /$ $\mathrm{ml}$ (1.2-8.6). Serum alpha subunit was not measured.

He underwent transsphenoidal surgery to remove the pituitary adenoma, and had a prompt improvement in his visual field. Immunoreactive staining of the tumour showed scattered TSH-secreting and FSH-secreting cells, but was negative for adrenocorticotrophic hormone, growth hormone, luteinising hormone, and prolactin.

Mild elevation of total thyroxine (213-241 nmol/l) and total triiodothyronine $(2.0-5.51 \mathrm{nmol} / \mathrm{l})$, with "inappropriately normal" TSH (1.72-2.01 mIU/l), persisted for 14 months after surgery. Because of concern that he may have "subclinical" TSH-dependent hyperthyroidism, he was treated with octreotide for two months, up to a dosage of 100 $\mu \mathrm{g}$ twice a day, with little change in his thyroid function tests. At that stage, review of his record revealed that triiodothyronine uptake, an indirect measure of serum thyroid binding capacity, had been persistently raised $(>2.0$, normal range $0.72-1.24$ ) since before he underwent pituitary surgery. TBG, free thyroxine, and free triiodothyronine were all measured for the first time some 16 months after he presented with his original symptoms. Serum free thyroxine was $10.3 \mathrm{pmol} / \mathrm{l}$ (10.3-34.8) and free triiodothyronine was $5.36 \mathrm{pmol} / \mathrm{l}$ (3.236.78). Serum TBG (Quest Diagnostics Inc, San Juan Capistrano, CA 92675) was considerably raised at $71 \mathrm{mg} / \mathrm{l}$ (normal range 17-36). These tests established the diagnosis of TBG excess, with otherwise normal thyroid function. He has remained symptomatically and clinically euthyroid. He initially declined testosterone replacement therapy despite persistently low serum testosterone levels, but started using testosterone gel with good clinical effect approximately two years after his pituitary surgery because of totally absent libido and diminished energy. Serum TBG remained raised at $57 \mathrm{mg} / \mathrm{l}$ during testosterone gel treatment.

\section{DISCUSSION}

It is not uncommon for patients with either a TSH-secreting pituitary adenoma or TBG excess to undergo treatment directed primarily at the thyroid, because of misattribution of the raised total thyroxine and triiodothyronine levels to primary hyperthyroidism, before the correct diagnosis is established. $^{34}$ The case history we describe illustrates some instructive variations on this theme of misdiagnosis.

Despite the absence of hyperthyroid symptoms, we believe the concern about a TSH-secreting adenoma was understandable. Just as one sometimes sees patients with primary hyperthyroidism with minimal or no hyperthyroid symptoms, the reasoning was that this patient may have had

Abbreviations: FSH, follicle stimulating hormone; MRI, magnetic resonance imaging; TBG, thyroid binding globulin; TSH, thyroid stimulating hormone 


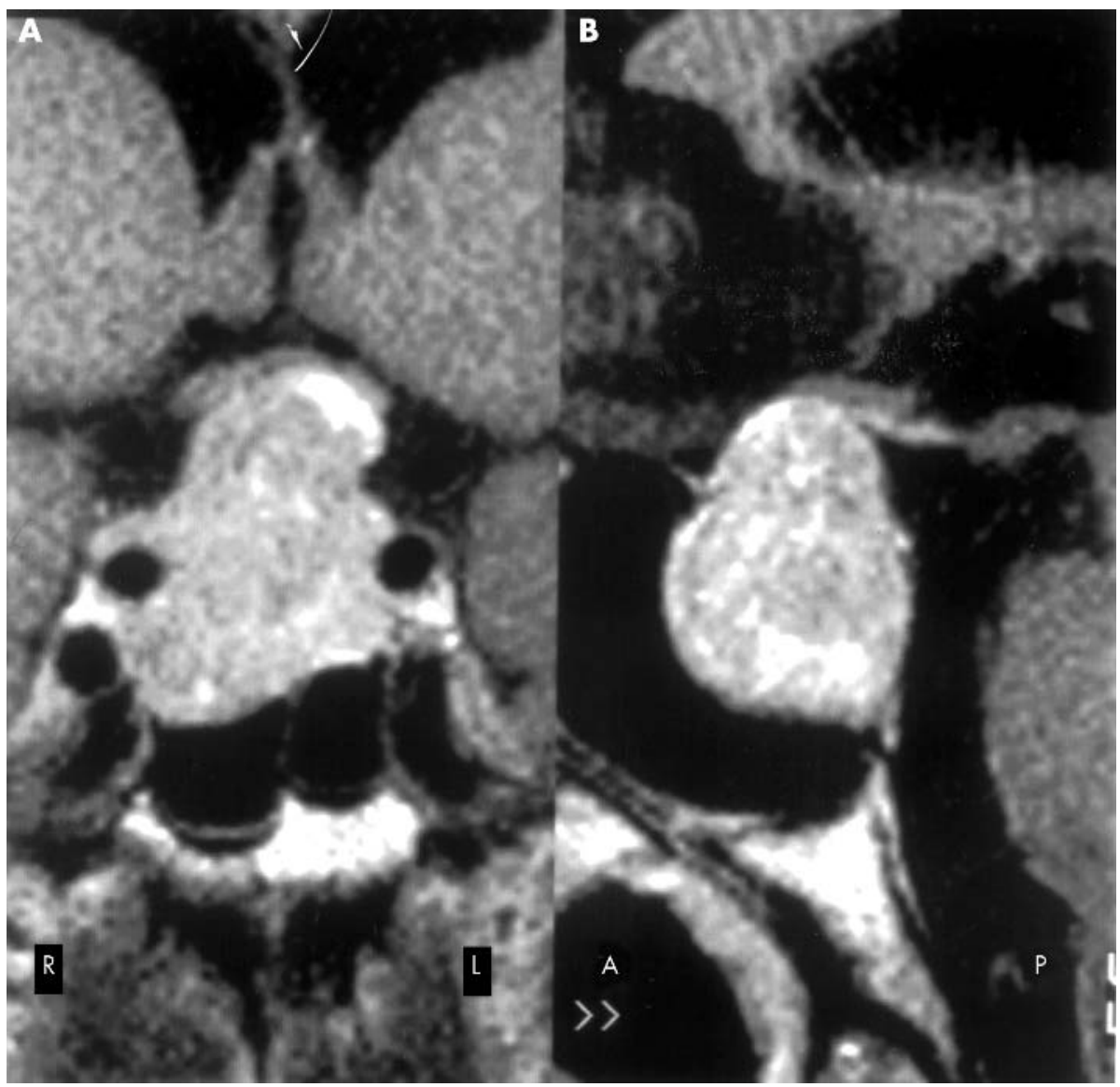

Figure 1 MRI scan (A, coronal; $B$, sagittal) demonstrating a pituitary lesion with suprasellar extension, impinging on the optic chiasm. asymptomatic central hyperthyroidism. The presence of scattered TSH-secreting, as well as FSH-secreting, cells reinforced this concern. However, it is clear, in retrospect, that he did not have central hyperthyroidism, and that the pituitary tumour was non-functioning. Measurement of serum alpha subunit may have led to this conclusion at an earlier stage. Focus on the triiodothyronine uptake test from the outset would also certainly have led to earlier diagnosis of TBG excess.

We believe the degree of TBG excess in this case is characteristic of a primary (familial) aetiology, though we don't know if any other family members have raised TBG levels and we have not investigated whether this raised TBG was the normal rather than the abnormal variant. Also we are not aware of any medical literature that relates TBG excess to pituitary tumorigenesis. Treatment with testosterone can be associated with a decrease in TBG levels, but we know of no evidence that the inverse is true. This patient's TBG level fell during testosterone gel treatment, but remained significantly increased.

The superiority of free, rather than total, thyroid hormone measurement to define true thyroid status is established beyond doubt. ${ }^{6}$ The present case is a further illustration of this. We support the view that routine measurement of total thyroid hormones and indirect indices of thyroid binding capacity should be abandoned entirely in favour of free thyroid hormone assays. ${ }^{7}$

Finally, we believe this is the first report of TBG excess occurring in conjunction with a pituitary macroadenoma containing TSH-producing cells.

\section{ACKNOWLEDGEMENT}

Presented at the 72nd meeting of the American Thyroid Association, 1999.

\section{Authors' affiliations}

M Soubhi Nizam, L Kennedy, Division of Endocrinology, Department of Medicine, University of Florida, Gainesville, Florida, USA

Correspondence to: Dr Laurence Kennedy, Division of Endocrinology and Metabolism, Department of Medicine, Room H2, Health Science Center, Box 100226, University of Florida, Gainesville, FL 32610-0226, USA; kenneal@medicine.ufl.edu

Submitted 28 April 2003

Accepted 18 June 2003

\section{REFERENCES}

1 Mindermann T, Wilson CB. Thyrotropin-producing pituitary adenomas. J Neurosurg 1993;79:521-7.

2 McDermott MT, Ridgway EC. Central hyperthyroidism. Endocrinol Metab Clin North Am 1998;27:187-203.

3 Beck-Peccoz P, Brucker-Davis F, Persani L, et al. Thyrotropin-secreting pituitary tumors. Endocrine Reviews 1996;17:610-38.

4 Bartalena L, Robbins J. Thyroid hormone transport proteins. Clin Lab Med 1993; 13:583-98.

5 Refetoff S. Inherited thyroxine-binding globulin abnormalities in man. Endocrine Reviews 1989;10:275-93.

6 Bartalena L, Bogazzi F, Brogioni S, et al. Measurement of serum free thyroid hormone concentration: an essential tool for the diagnosis of thyroid dysfunction. Horm Res 1996;45:142-7.

7 Dickey RA. Let's get real about actual costs of thyroid testing. Endocrine Practice 1999:5:54(letter). 